\title{
Anxiety Symptoms in Adult Celiac Patients and the Effect of a Gluten-Free Diet: An Iranian Nationwide Study
}

\author{
Mohammad Rostami-Nejad ${ }^{a}$ Nazanin Taraghikhah ${ }^{b}$ Carolina Ciacci $^{c}$ \\ Mohamad Amin Pourhoseingholi ${ }^{d}$ Farnoush Barzegar $^{a}$ \\ Mostafa Rezaei-Tavirani ${ }^{\mathrm{e}}$ David Aldulaimi ${ }^{\mathrm{f}}$ Mohammad Reza Zali ${ }^{\mathrm{a}}$
}

${ }^{a}$ Gastroenterology and Liver Diseases Research Center, Research Institute for Gastroenterology and Liver Diseases,

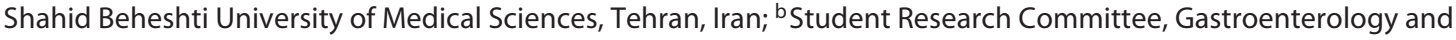
Liver Diseases Research Center, Shahid Beheshti University of Medical Sciences, Tehran, Iran; ' Coeliac Center at Department of Medicine and Surgery, Scuola Medica Salernitana, University of Salerno, Salerno, Italy; ${ }^{\mathrm{d} B a s i c}$ and Molecular Epidemiology of Gastrointestinal Disorders Research Center, Research Institute for Gastroenterology and

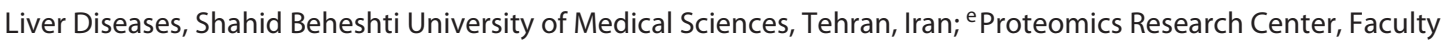
of Paramedical Sciences, Student Research Committee, Shahid Beheshti University of Medical Sciences, Tehran, Iran; ${ }^{f}$ Consultant Gastroenterologist, South Warwickshire Foundation Trust, Warwick, UK

\section{Keywords}

Celiac disease · Anxiety · Iran · Gluten-free diet ·

Zung Self-Rating Anxiety Scale

\begin{abstract}
Introduction: Psychiatric disorders, especially anxiety, are considered extraintestinal manifestations of celiac disease (CD). Objective: This study aims to evaluate the level of anxiety in treated patients with CD in Iran. Methods: A total of 283 CD patients (190 female, 93 male) were enrolled in a study during 2016-2018 from 9 centers in Iran. The Zung Self-Rating Anxiety Scale questionnaire was completed. The anxiety index was calculated. Also, demographic data and the duration of treatment with a gluten-free diet (GFD) were recorded. Data were analyzed by SPSS version 20. Results: Anxiety symptoms were reported in $67.8 \%$ of patients. Female patients had a higher anxiety index than male patients.
\end{abstract}

Duration of treatment with a GFD did not influence the anxiety index $(17.3 \%$ were on a GFD for $<1$ year, $33.6 \%$ for $1-2$ years, and $49.1 \%$ had GFD for $>2$ years; $p=0.86)$. Conclusions: These results suggest that anxiety symptoms are common among patients, especially females, with CD in Iran and GFD duration has no effect on their improvement.

(c) 2020 The Author(s)
Published by S. Karger AG, Basel

\section{Introduction}

Celiac disease (CD) is the most common gluten-related disease and the result of both environmental and genetic factors. This chronic disease is characterized by small intestine villous atrophy, due to the ingestion of gluten. CD is diagnosed by serological tests and intestinal

N. Taraghikhah is equal to the first author.

\begin{tabular}{ll}
\hline KARGER & $\begin{array}{l}\text { @ 2020 The Author(s) } \\
\text { Published by S. Karger AG, Basel Openger }\end{array}$ \\
E-Mail karger@karger.com & This article is licensed under the Creative Commons Attribution- \\
www.karger.com/iid & $\begin{array}{l}\text { NonCommercial-NoDerivatives 4.0 International License (CC BY- } \\
\text { NC-ND) (http://www.karger.com/Services/OpenAccessLicense). } \\
\text { Usage and distribution for commercial purposes as well as any dis- } \\
\text { tribution of modified material requires written permission. }\end{array}$
\end{tabular}

Mohamad Amin Pourhoseingholi, Basic and Molecular Epidemiology of Gastrointestinal Disorders Research Center Research Institute for Gastroenterology and Liver Diseases Shahid Beheshti University of Medical Sciences, Tehran (Iran) E-Mail aminphg@gmail.com 
biopsy [1]. The worldwide prevalence of CD is $1 \%$ in the general population and $0.3-2.9 \%$ in children, with marked geographical variation [2]. In Iran, the prevalence of CD is considered to be $1 \%$ in the general population $[3,4]$.

$\mathrm{CD}$ can develop at any age and present with a wide variety of gastrointestinal and non-gastrointestinal symptoms. Furthermore, some CD patients may be asymptomatic [5]. Common presentations of CD include chronic diarrhea, malabsorption, abdominal pain, weight loss, and steatorrhea. Extraintestinal symptoms include hair loss, mouth ulceration, and fatigue. Studies have suggested that $\mathrm{CD}$ is associated with psychiatric conditions, such as anxiety, depression, and mood disorders, and, in rare cases, suicide has been reported in patients with CD [610]. This chronic disorder affects not only health but also the patient's overall well-being and quality of life. Depression and anxiety are the most common psychiatric conditions, diagnosed in adults and pediatric CD patients [11, 12]. The mechanisms underlying the development of mental health problems in patients with CD remain uncertain. Some studies have suggested mechanisms including a deficiency of amino acids such as tryptophan [1315] and central serotonin hypofunction [16] as possible causes. Alternative etiological factors may include cerebral hypoperfusion, vitamin deficiency due to malabsorption, or hyper-homocysteinemia. Hyper-homocystinuria might compromise the blood-brain barrier [1719]. Other studies have suggested that patient anxiety and depression could relate to the perception of the illness, treatment, and concerns regarding socializing with others and a feeling of loneliness and worry $[20,21]$.

The effect of gluten-free diet (GFD) on psychological symptoms such as anxiety remains uncertain, but some researchers have suggested that anxiety may improve after starting a GFD [22,23]. Some researchers have claimed that celiac patients have a higher risk of anxiety than the general population. Butwicka et al. [24] suggested that pediatric patients with $\mathrm{CD}$ have a 1.4 -fold higher risk of psychiatric disorders than healthy children. A study by Fera et al. [25] revealed that CD patients suffered from higher anxiety and depression rates than the controlled group. The aim of this study is to evaluate the level of anxiety among Iranian patients with CD and the effect of a GFD.

\section{Materials and Methods}

\section{Participants}

This was a nationwide study that recruited 283 asymptomatic CD patients, on a GFD, from seven cities across different parts of Iran (Tehran in the center, Sari and Gorgan in the north, Ilam in the west, Mashhad in the east, Gonabad in the northeast, and Tabriz in the northwest) and who had been admitted to outpatient clinics from October 2016 to February 2018. Patients were diagnosed by gastroenterologists according to positive serological tests (tTG-IgA) and histological data of small intestinal biopsy based on Marsh criteria [26].

\section{Materials and Procedure}

In our study, we used a questionnaire. The questionnaire contained two parts. The first part related to demographic information such as age, gender, education level, marital status, family history of CD, and duration of GFD, and the second part consisted of 20 anxiety assessment questions. The second part contained questions regarding anxiety symptoms and the Zung Self-Rating Anxiety Scale to assess the prevalence and quantify anxiety symptoms. Within the 20 anxiety assessment questions, five enquired about affective symptoms like anxiety, fear, panic, and mental disintegration. The other 15 enquired about somatic symptoms such as tremor, body pain, weakness, restlessness, palpitation, dizziness, faintness, dyspnea, nausea and vomiting, urinary frequency, sweating, face flushing, insomnia, and nightmare.

Patients scored each question from 1 to 4 (based on the following replies: a little part of the time, some part of the time, a good part of the time, most of the time). The total score ranged from 20 to 80 . An anxiety index score was calculated for each patient. The anxiety index score was used to determine each patient's anxiety level using the following values $[27,28]$ :

- 20-44, normal range

- 45-59, mild to moderate anxiety levels

- 60-74, marked to severe anxiety levels

- 75-80, extreme anxiety levels

The questionnaire was distributed in celiac clinics to patients, aged older than 15 years, who were attending for a routine checkup and were willing to participate in this study. The study was approved by the ethics committee of the Research Institute for Gastroenterology and Liver Disease, Shahid Beheshti University of Medical Science, Tehran, Iran and all participants signed the consent form.

\section{Data Analyses}

The statistical package for social sciences (SPSS version 20 for Windows) was used for the statistical analysis. The variables in this study included sex (male, female), age $(>30,<30)$, marital status (married, single), history of CD (yes, no), duration of GFD (less than 1 year, between 1 and 2 years, more than 2 years), and educational achievement. The educational level includes illiterate, under diploma (categorized as the low educational group), diploma, and academic (categorized as high educational group). The variables' values were given as the mean, standard deviation, minimum, and maximum. Independent samples $t$ test was applied as a parametric test to compare two groups of continuous variables with normal distribution, and Leven's test was used to compare two groups of variables without normal distribution. Numerical data were processed by ANOVA and nominal data utilizing $t$ test, applying Yates correction when required. Also, Mann-Whitney nonparametric test was performed for ordinal variables. All data were presented as mean and with a $95 \%$ confidence interval of difference. A $p$ value of $<0.05$ was considered to be significant in this study. 
Table 1. Distribution of demographic factors according to number (percent) among males and females

\begin{tabular}{lllrc}
\hline & & Males & Females & $p$ value \\
\hline Marital status & married & $48(52.2)$ & $108(57.1)$ & 0.44 \\
& single & $44(47.8)$ & $81(42.9)$ & \\
\hline Family history of celiac disease & yes & $11(11.8)$ & $36(19.0)$ & 0.17 \\
& no & $82(88.2)$ & $153(81.0)$ & \\
\hline Age & $>30$ years & $46(49.5)$ & $79(41.6)$ & 0.25 \\
& $<30$ years & $47(50.5)$ & $111(58.4)$ & \\
\hline Duration of gluten-free diet & $<$ year & $15(16.1)$ & $34(17.9)$ & 0.02 \\
& $1-2$ years & $41(44.1)$ & $54(28.4)$ & \\
\hline Education level & $>2$ years & $37(39.8)$ & $102(53.7)$ & \\
\hline Residential location & low educated & $36(39.1)$ & $71(38.0)$ & 0.89 \\
& highly educated & $56(60.9)$ & $116(62.0)$ & \\
\hline
\end{tabular}

Table 2. Comparison of anxiety percent in celiac disease patients by gender, marital status, family history of celiac disease, age, education level, and duration of gluten-free diet

\begin{tabular}{|c|c|c|c|c|}
\hline & & Frequency (\%) & Anxiety score & $p$ value \\
\hline Gender & $\begin{array}{l}\text { female } \\
\text { male }\end{array}$ & $\begin{array}{r}190(67.1) \\
93(32.9)\end{array}$ & $\begin{array}{l}53.75 \\
48.68\end{array}$ & 0.003 \\
\hline Marital status & $\begin{array}{l}\text { married } \\
\text { single }\end{array}$ & $\begin{array}{l}156(55.1) \\
127(44.9)\end{array}$ & $\begin{array}{l}53.46 \\
50.39\end{array}$ & 0.06 \\
\hline Family history of celiac disease & $\begin{array}{l}\text { yes } \\
\text { no }\end{array}$ & $\begin{array}{r}47(16.6) \\
236(83.4)\end{array}$ & $\begin{array}{l}51.88 \\
52.12\end{array}$ & 0.91 \\
\hline Age & $\begin{array}{l}>30 \text { years } \\
<30 \text { years }\end{array}$ & $\begin{array}{l}158(55.8) \\
125(44.2)\end{array}$ & $\begin{array}{l}52.85 \\
51.12 \\
\end{array}$ & 0.29 \\
\hline Duration of gluten-free diet & $\begin{array}{l}<1 \text { year } \\
1-2 \text { years } \\
>2 \text { years }\end{array}$ & $\begin{array}{r}49(17.3) \\
95(33.6) \\
139(49.1)\end{array}$ & $\begin{array}{l}51.22 \\
51.97 \\
52.46\end{array}$ & 0.86 \\
\hline Education level & $\begin{array}{l}\text { low educated } \\
\text { highly educated }\end{array}$ & $\begin{array}{l}107(37.8) \\
176(62.2)\end{array}$ & $\begin{array}{l}50.83 \\
52.85\end{array}$ & 0.23 \\
\hline Residential location & $\begin{array}{l}\text { urban } \\
\text { rural }\end{array}$ & $\begin{array}{r}236(83.4) \\
47(16.6)\end{array}$ & $\begin{array}{l}51.78 \\
53.62\end{array}$ & 0.40 \\
\hline
\end{tabular}

\section{Results}

The study population included 283 patients, of whom 190 were women $(67.1 \%)$. The participants were between 15 and 66 years of age, and the mean age of the study group was $32.5 \pm 14.5$ years. $44.2 \%$ (125) were less than 30 years of age. $55.1 \%$ of patients (156) were married and $16.6 \%$ (47) reported a family history of CD. $37.8 \%$ (176) of patients were in the low educated level group. In terms of the duration of the GFD, $17.3 \%$ (49) reported less than 1 year, 33.6\% (95) between 1 and 2 years, and 49.1\% (139) had been on the diet for more than 2 years. $83.4 \%$ of patients (236) were resident in an urban area. The demographics between males and females were not significantly different. However, the duration of the GFD was longer in females, compared to males $(p=0.02)$ (Table 1). 
Table 3. Mean scores of the Zung anxiety scale in celiac disease (CD) patients divided by gender

\begin{tabular}{|c|c|c|c|}
\hline Questions & $\begin{array}{l}\text { CD women } \\
\text { (mean scores } \\
\pm \mathrm{SD})\end{array}$ & $\begin{array}{l}\text { CD men } \\
\text { (mean scores } \\
\pm \mathrm{SD})\end{array}$ & $p$ value \\
\hline $1 \mathrm{I}$ feel more nervous and anxious than usual. & $2.48 \pm 1.06$ & $2.22 \pm 1.01$ & 0.06 \\
\hline 2 I feel afraid for no reason at all. & $2.07 \pm 1.05$ & $1.89 \pm 0.91$ & 0.23 \\
\hline 3 I get upset easily or feel panicky. & $2.17 \pm 1.06$ & $1.78 \pm 0.87$ & 0.007 \\
\hline 4 I feel like I'm falling apart and going to pieces. & $1.89 \pm 1.01$ & $1.66 \pm 0.88$ & 0.07 \\
\hline $5 \mathrm{I}$ feel that everything is all right and nothing bad will happen. & $3.01 \pm 0.91$ & $2.98 \pm 0.92$ & 0.76 \\
\hline $6 \mathrm{My}$ arms and legs shake and tremble. & $2.25 \pm 1.06$ & $1.84 \pm 0.91$ & 0.002 \\
\hline 7 I am bothered by headaches, neck and back pain. & $2.30 \pm 1.11$ & $1.86 \pm 0.98$ & 0.001 \\
\hline $8 \mathrm{I}$ have fainting spells or feel like it. & $1.42 \pm 0.86$ & $1.38 \pm 0.89$ & 0.43 \\
\hline 9 I can breathe in and out easily. & $2.37 \pm 1.25$ & $2.36 \pm 1.38$ & 0.89 \\
\hline 10 I get feelings of numbness and tingling in my fingers and toes. & $2.10 \pm 1.06$ & $1.66 \pm 0.93$ & $<0.001$ \\
\hline 11 I am bothered by stomach aches or indigestion. & $2.14 \pm 1.01$ & $1.90 \pm 0.95$ & 0.06 \\
\hline 12 I feel weak and get tired easily. & $2.38 \pm 1.04$ & $2.34 \pm 1.01$ & 0.75 \\
\hline 13 I feel calm and can sit still easily. & $1.64 \pm 0.99$ & $2.38 \pm 1.03$ & 0.05 \\
\hline 14 I can feel my heart beating fast. & $2.02 \pm 0.97$ & $2.00 \pm 1.02$ & 0.78 \\
\hline 15 I am bothered by dizzy spells. & $1.90 \pm 0.99$ & $1.63 \pm 0.89$ & 0.02 \\
\hline 16 I have to empty my bladder often. & $1.77 \pm 1.01$ & $1.76 \pm 0.93$ & 0.81 \\
\hline 17 My hands are usually dry and warm. & $1.95 \pm 1.05$ & $1.70 \pm 0.92$ & 0.07 \\
\hline 18 My face gets hot and blushes. & $1.95 \pm 1.03$ & $1.57 \pm 0.76$ & 0.007 \\
\hline 19 I fall asleep easily and get a good night's rest. & $2.44 \pm 1.06$ & $2.29 \pm 1.16$ & 0.26 \\
\hline 20 I have nightmares. & $1.75 \pm 0.93$ & $1.75 \pm 0.94$ & 0.95 \\
\hline
\end{tabular}

The anxiety index in our study population was high, with a mean percentage of $52.08 \%$ (mean score $=41.67$, min. percent $=25$ and max. percent $=92.5)$. According to the anxiety index, only $32.2 \%$ of patients had a normal level of anxiety, $41 \%$ had a mild to moderate level of anxiety, $19.4 \%$ had severe anxiety, and $7.4 \%$ had extreme anxiety levels.

Multivariate analysis revealed that anxiety rate was significantly higher for women than men. Other demographic factors indicated no significant association with anxiety index; specifically, there was no relationship between anxiety index and the GFD duration $(p=0.86)$. The results are presented in Table 2.

The effect of gender on each anxiety scale question was studied using the Mann-Whitney test. Feeling upset or panicky was higher in women, compared to men $(p=0.007)$. Also, suffering with a feeling of physical shaking in arms and legs $(p=0.002)$, experiencing headaches, neck and back pain $(p=0.001)$, experiencing feelings of numbness and tingling in fingers and toes $(p<0.001)$ and dizzy spells $(p=0.02)$, and experiencing hot flushes in their face $(p=0.007)$ were higher in women (Table 3 ).

\section{Discussion}

The results of this study showed that anxiety symptoms are frequent among Iranian CD patients and their frequency is higher among women than men. In particular, women reported physical signs of anxiety, such as tremors of arms and legs, headaches and back pain, numbness of extremities, dizzy spells, and a flushed face more frequently than men.

However, other variables under examination, such as the duration of treatment with a GFD, did not influence the presence of anxiety symptoms. To our knowledge, this is the first study on the topic in the Middle East.

Psychiatric symptoms such as anxiety and depression are potentially challenging extraintestinal symptoms that can occur before or after a diagnosis of CD [29]. The mechanisms of anxiety associated with $\mathrm{CD}$ are not fully understood. Tryptophan deficiency and central serotoninergic hypofunction are possible causes [10]. Addolorato et al. [11] have suggested that anxiety is probably due to being affected by a chronic disease, but the depressive symptoms may be a characteristic of CD [15]. Some researchers have suggested that $\mathrm{CD}$ patients, both adults and children, are more predisposed to anxiety than the general population [30]. In the first report, Hallert and 
Derefeldt [31] in 1982 showed evidence of a relationship between CD and psychiatric disorders. Butwicka et al. [24] showed that children with CD have a 1.4-fold higher risk of anxiety than healthy children and childhood CD is identified as a risk factor for anxiety disorders. Fera et al. [25] evaluated the level of anxiety by State-Trait Anxiety Inventory (STAI) questionnaires in CD patients. They reported higher levels of anxiety than healthy controls. In the study by Addolorato et al. [32], 75\% of CD patients were positive for state anxiety, and $52.3 \%$ of $\mathrm{CD}$ patients were positive for trait anxiety, based on the STAI test. In our survey, anxiety was at $52.08 \%$ (mean score: 41.67 ), and this high anxiety level is in agreement with former studies.

Some investigations have shown no relationship between the anxiety complaints observed in CD patients and demographics such as gender, age, and educational level variables [33]. For example, Fera et al. [25] revealed that anxiety did not depend on demographic variables (age, gender, education, employment status). Some investigations described a higher level of anxiety in female CD patients compared to males. Our results showed that female CD patients feel more upset, panicky and have more somatic symptoms than male CD patients. JanssonKnodell et al. [34] reported that the prevalence of intestinal and extraintestinal manifestations of CD is higher in women. Hallert et al. [35] believed that women express more concerns and worries about the impact of the disease on their social relations, and they have difficulty managing their disease. Our findings are consistent with the results of that study.

As the duration of a GFD for women was significantly longer than for men in our study, we hypothesize that this variable may affect the higher prevalence of anxiety in women. Addolorato et al. [29] and Ciacci et al. [15] claimed that anxiety levels decrease after starting a GFD, but depression symptoms remain. Campagna et al. [36], in their review, believed that a GFD is useful in the treatment of depression, anxiety, and neurological complications. The finding contrasts with studies that have reported no association between depression/anxiety and GFD compliance. Furthermore, studies have suggested that treatment with a GFD does not prevent the development of depression or anxiety [25, 37, 38]. In the study by Zingone et al. [39], a GFD did not induce any improvement in the STAI scores between untreated $C D$ patients and CD patients on a GFD. Similar to the study by Zingone et al. [39], our results confirmed that the duration of a GFD had no noticeable effect on anxiety. This finding is in contrast with the study by Addolorato et al. [29], which found a significant improvement in anxiety after 1 year on a GFD. One possible expla- nation is that patients diagnosed with $\mathrm{CD}$ in Iran may struggle to fully comply with a GFD because "gluten-free products" may be inaccessible or very expensive. There may also be undefined contamination of gluten-free products. So subsequent studies could target the compliance of GFD and the accessibility to "gluten-free products" to clarify their potential impact on a patient's anxiety.

In conclusion, we observed a high incidence of anxiety among the Iranian CD population, especially more frequently in women than men, with no association with age, marital status, family history, educational state, or duration of a GFD. In light of the present results, gastroenterologists and healthcare professionals should provide psychiatric support to $\mathrm{CD}$ patients. As anxiety in $\mathrm{CD}$ women on a GFD is higher than in men, screening for anxiety in $\mathrm{CD}$ women both at diagnosis and also on a GFD should be considered. Besides, since the prevalence of $\mathrm{CD}$ is high in Iran, CD screening among patients with anxiety would be recommended as an effective protocol for finding new cases of CD in Iran and psychiatrists could pay attention to this disorder as a cause of psychiatric symptoms.

\section{Acknowledgements}

We appreciate the Shahid Beheshti University of Medical Sciences, Tehran, Iran.

\section{Statement of Ethics}

The study was approved by the ethics committee of the Research Institute for Gastroenterology and Liver Disease, Shahid Beheshti University of Medical Science, Tehran, Iran and all participants signed informed consent.

\section{Disclosure Statement}

There is no conflict of interest.

\section{Funding Sources}

This study was supported by National Institute for Medical Research Development (Grant No. 971025).

\section{Author Contributions}

M. Rostami-Nejad and M.A. Pourhoseingholi provided the research topic and design the method. M. Rostami-Nejad, M.A. Pourhoseingholi, N. Taraghikhah, C. Ciacci, and F. Barzegar collected data and prepared the datasheet. M. Rezaei-Tavirani, D. Aldulaimi, and M. Reza Zali consulted the study. All authors contributed equally in manuscript writing and revising the final version.
Rostami-Nejad et al. 


\section{References}

1 Esenyel S, Unal F, Vural P. Depression and anxiety in child and adolescents with followup celiac disease and in their families. Turk J Gastroenterol. 2014 Aug;25(4):381-5.

2 Ludvigsson JF, Green PH. Clinical management of coeliac disease. J Intern Med. 2011 Jun;269(6):560-71.

3 Mohammadibakhsh R, Sohrabi R, Salemi M, Mirghaed MT, Behzadifar M. Celiac disease in Iran: a systematic review and meta-analysis. Electron Physician. 2017 Mar;9(3):388395.

4 Rostami Nejad M, Rostami K, Emami M, Zali M, Malekzadeh R. Epidemiology of celiac disease in iran: a review [Review]. Middle East J Dig Dis. 2011 Mar;3(1):5-12.

5 Rostami Nejad M, Rostami K, Pourhoseingholi MA, Nazemalhosseini Mojarad E, Habibi M, Dabiri H, et al. Atypical presentation is dominant and typical for coeliac disease. J Gastrointestin Liver Dis. 2009 Sep;18(3):285-91.

6 Hill ID, Dirks MH, Liptak GS, Colletti RB, Fasano A, Guandalini S, et al.; North American Society for Pediatric Gastroenterology, Hepatology and Nutrition. Guideline for the diagnosis and treatment of celiac disease in children: recommendations of the North American Society for Pediatric Gastroenterology, Hepatology and Nutrition. J Pediatr Gastroenterol Nutr. 2005 Jan; 40(1):1-19.

7 Alaedini A, Green PH. Narrative review: celiac disease: understanding a complex autoimmune disorder [Review]. Ann Intern Med. 2005 Feb;142(4):289-98.

8 Corazza GR, Gasbarrini G. Coeliac disease in adults [Review]. Baillieres Clin Gastroenterol. 1995 Jun;9(2):329-50.

9 Capristo E, Mingrone G, Addolorato G, Greco AV, Corazza GR, Gasbarrini G. Differences in metabolic variables between adult coeliac patients at diagnosis and patients on a gluten-free diet. Scand J Gastroenterol. 1997 Dec; 32(12):1222-9.

10 Addolorato G, De Lorenzi G, Abenavoli L, Leggio L, Capristo E, Gasbarrini G. Psychological support counselling improves glutenfree diet compliance in coeliac patients with affective disorders. Aliment Pharmacol Ther. 2004 Oct;20(7):777-82.

11 Addolorato G, Stefanini GF, Capristo E, Caputo F, Gasbarrini A, Gasbarrini G. Anxiety and depression in adult untreated celiac subjects and in patients affected by inflammatory bowel disease: a personality "trait" or a reactive illness? Hepatogastroenterology. 1996 Nov-Dec;43(12):1513-7.

12 Pietzak MM. Follow-up of patients with celiac disease: achieving compliance with treatment. Gastroenterology. 2005 Apr;128(4 Suppl 1):S135-41.

13 Hallert C, Aström J, Sedvall G. Psychic disturbances in adult coeliac disease. III. Reduced central monoamine metabolism and signs of depression. Scand J Gastroenterol. 1982 Jan; $17(1): 25-8$
14 Burke P, Elliott M. Depression in pediatric chronic illness. A diathesis-stress model [Review]. Psychosomatics. 1999 Jan-Feb;40(1): 5-17.

15 Ciacci C, Iavarone A, Mazzacca G, De Rosa A; C. CIACCI, A. IAVARONE, G. MAZZACCA. Depressive symptoms in adult coeliac disease. Scand J Gastroenterol. 1998 Mar; 33(3):247-50.

16 Zeisel SH, Growdon JH, Wurtman RJ, Magil SG, Logue M. Normal plasma choline responses to ingested lecithin. Neurology. 1980 Nov;30(11):1226-9.

17 Addolorato G, Di Giuda D, De Rossi G, Valenza V, Domenicali M, Caputo F, et al. Regional cerebral hypoperfusion in patients with celiac disease. Am J Med. 2004 Mar; 116(5):312-7.

18 Hallert C, Svensson M, Tholstrup J, Hultberg B. Clinical trial: B vitamins improve health in patients with coeliac disease living on a gluten-free diet. Aliment Pharmacol Ther. 2009 Apr;29(8):811-6.

19 Ferretti A, Parisi P, Villa MP. The role of hyperhomocysteinemia in neurological features associated with coeliac disease. Med Hypotheses. 2013 Oct; $81(4): 524-31$.

20 Hallert C, Grännö C, Grant C, Hultén S, Mid hagen G, Ström M, et al.; C. Hallert, C. Grännö, C. Grant, S. Quality of life of adult coeliac patients treated for 10 years. Scand J Gastroenterol. 1998 Sep;33(9):933-8.

21 de Rosa A, Troncone A, Vacca M, Ciacci C. Characteristics and quality of illness behavior in celiac disease. Psychosomatics. 2004 JulAug;45(4):336-42.

22 Nachman F, del Campo MP, González A, Corzo L, Vázquez H, Sfoggia C, et al. Longterm deterioration of quality of life in adult patients with celiac disease is associated with treatment noncompliance. Dig Liver Dis. 2010 Oct;42(10):685-91.

23 van Hees NJ, Van der Does W, Giltay EJ. Coeliac disease, diet adherence and depressive symptoms. J Psychosom Res. 2013 Feb;74(2): 155-60.

24 Butwicka A, Lichtenstein P, Frisén L, Almqvist C, Larsson H, Ludvigsson JF. Celiac Disease Is Associated with Childhood Psychiatric Disorders: A Population-Based Study. J Pediatr. 2017 May; 184:87-93.e1.

25 Fera T, Cascio B, Angelini G, Martini S, Guidetti CS. Affective disorders and quality of life in adult coeliac disease patients on a gluten-free diet. Eur J Gastroenterol Hepatol. 2003 Dec; 15(12):1287-92.

26 Rostami K, Marsh MN, Johnson MW, Mohaghegh H, Heal C, Holmes G, et al. ROC-king onwards: intraepithelial lymphocyte counts, distribution \& role in coeliac disease mucosal interpretation. Gut. 2017 Dec;66(12):2080-6.
27 Zung WW. A rating instrument for anxiety disorders. Psychosomatics. 1971 Nov-Dec; 12(6):371-9.

28 Zung WW. SAS, self-rating anxiety scale. ECDEU assessment manual for psychopharmacology, revised edition. Rockville, Maryland, 1976: 337-40.

29 Addolorato G, Capristo E, Ghittoni G, Valeri $\mathrm{C}$, Mascianà $\mathrm{R}$, Ancona $\mathrm{C}$, et al. Anxiety but not depression decreases in coeliac patients after one-year gluten-free diet: a longitudinal study. Scand J Gastroenterol. 2001 May;36(5): 502-6.

30 Zingone F, Swift GL, Card TR, Sanders DS, Ludvigsson JF, Bai JC. Psychological morbidity of celiac disease: A review of the literature. United European Gastroenterol J. 2015 Apr; 3(2):136-45.

31 Hallert C, Derefeldt T. Psychic disturbances in adult coeliac disease. I. Clinical observations. Scand J Gastroenterol. 1982 Jan;17(1): 17-9.

32 Addolorato G, Mirijello A, D’Angelo C, Leggio L, Ferrulli A, Abenavoli L, et al. State and trait anxiety and depression in patients affected by gastrointestinal diseases: psychometric evaluation of 1641 patients referred to an internal medicine outpatient setting. Int J Clin Pract. 2008 Jul;62(7):1063-9.

33 Ciacci C, D’Agate C, De Rosa A, Franzese C, Errichiello S, Gasperi V, et al. Self-rated quality of life in celiac disease. Dig Dis Sci. 2003 Nov;48(11):2216-20.

34 Jansson-Knodell CL, King KS, Larson JJ, Van Dyke CT, Murray JA, Rubio-Tapia A. Gender-Based Differences in a Population-Based Cohort with Celiac Disease: More Alike than Unalike. Dig Dis Sci. 2018 Jan;63(1):184-92.

35 Hallert C, Grännö C, Hultén S, Midhagen G, Ström M, Svensson $\mathrm{H}$, et al. Living with coeliac disease: controlled study of the burden of illness. Scand J Gastroenterol. 2002 Jan;37(1): $39-42$.

36 Campagna G, Pesce M, Tatangelo R, Rizzuto A, La Fratta I, Grilli A. The progression of coeliac disease: its neurological and psychiatric implications. Nutr Res Rev. 2017 Jun;30(1): 25-35.

37 Pynnönen PA, Isometsä ET, Verkasalo MA, Kähkönen SA, Sipilä I, Savilahti E, et al. Gluten-free diet may alleviate depressive and behavioural symptoms in adolescents with coeliac disease: a prospective follow-up case-series study. BMC Psychiatry. 2005 Mar;5(1) 14.

38 Pynnönen PA, Isometsä ET, Aronen ET, Verkasalo MA, Savilahti E, Aalberg VA. Mental disorders in adolescents with celiac disease. Psychosomatics. 2004 Jul-Aug;45(4):325-35.

39 Zingone F, Siniscalchi M, Capone P, Tortora $\mathrm{R}$, Andreozzi P, Capone E, et al. The quality of sleep in patients with coeliac disease. Aliment Pharmacol Ther. 2010 Oct;32(8): 1031-6. 